\title{
Towards measuring the informal city: a societal metabolism
}

\section{approach}

Suzanne Smit, Josephine K Musango, Zora Kovacic, Alan C Brent

\section{Summary}

The rapid growth of urban informal settlements or slums, poses a particular challenge for balancing developmental and environmental goals. In South Africa, high levels of inequality, poverty and unemployment contribute to widespread migration. The influx of migrant workers to cities however is rarely matched with adequate housing and infrastructure, resulting in the formation and growth of urban informal settlements. Despite the persistence of the slum phenomenon, very few studies provide an in-depth understanding of the metabolic processes that link these spaces, and informal economies, to the broader urban environment and economy. This article therefore utilised a multi-scale integrated assessment of the societal and ecosystem metabolism (MuSIASEM) approach to examine human activity and land use in Enkanini, an urban informal settlement in Stellenbosch, South Africa. The results highlight a number of issues to be addressed through spatial, developmental, and local economic policy such as the need for improved transport linkages. The time use results show that Enkanini is a net provider of labour to the surrounding area. Further, geographic mapping indicates Enkanini as a small, but vibrant, informal economy, whilst being grossly underserviced in terms of water, waste, and sanitation infrastructure. Key implications are discussed in terms of the theoretical, methodological, societal and policy impact of the study, including the need for city observatories that conduct regular data collection and analysis. 
Keywords: Urban slum; informal settlement; urban metabolism; societal metabolism; MuSIASEM

\section{Address correspondence to:}

Suzanne Smit, School of Public Leadership, Stellenbosch University, Private bag X1, Matieland, 7602, Stellenbosch, South Africa. Email: informalgreeneconomy@gmail.com; Web address: www.umama-africa.com 


\section{<heading level $1>$ Introduction}

Increasing urbanisation, coupled with the proliferation of slums, particularly in developing countries, give rise to the need for a holistic approach and understanding of the functioning of slums, and their connection to the wider urban system (Smit et al. 2017; Guibrunet and Castán Broto 2015; Guibrunet et al. 2016; Attia and Khalil, 2015). Informal settlements, or slums are recognised by the United Nations Human Settlement programme (UN-Habitat 2010) as households lacking any of the following conditions: (i) access to improved water; (ii) access to improved sanitation facilities; (iii) sufficient living area - not overcrowded; (iv) structural quality/durability of dwellings; and (v) security of tenure. The analysis of slums or informal settlements should not solely be based on their physical, geographical, and legal characteristics (Smit et al. 2017) but should also consider their societal metabolism in relation to the overall city. This is because slums are not self-evident units of analysis and are connected to the broader urban metabolism in many different ways.

Urban metabolism provides a conceptual framework for understanding the functioning of cities with regard to the technical, socioeconomic, and socio-ecological processes that result in growth, production and consumption of material flows, and the elimination of waste; thereby influencing sustainable urban planning and design (Kennedy et al. 2007; Kennedy et al. 2011; Pincetl et al. 2012; Currie and Musango 2016). While urban metabolism is useful for shaping urban sustainability (Kennedy and Hoornweg 2012), existing studies have not effectively engaged with the institutional and political contexts, which shape and influence urban material flows (Pincetl et al. 2012; Guibrunet et al. 2016; Currie and Musango 2016). This has led several authors to call for a 'politicization' of urban metabolism (Newell and Cousins 2015; Smit et al. 2017), and the inclusion 
of urban informal settlements or slums in the study of urban metabolism (Smit et al. 2017; Guibrunet et al. 2016, 2015; Attia and Khalil 2015; Currie and Musango 2016). Furthermore, effective policy and infrastructure planning requires understanding the variations of resource consumption within the city (Horta and Keirstead 2016). This implies that urban metabolism studies should explicitly incorporate urban informality to uncover the environmental, social, and economic aspects of resource distribution, and to unpack the politics embedded in material flows (Guibrunet and Castán Broto 2015; Musango et al. 2017).

Conventional urban metabolism methods ${ }^{1}$ tend to incorporate accounting methods that rely on secondary data (Beloin-Saint-Pierre et al. 2016), or statistical methods for downscaling aggregate data (Horta and Keirstead 2016; Currie and Musango, 2016), rather than utilising primary data based on bottom-up approaches. These studies therefore tend to ignore informal flows and processes of informal settlements, which are deemed 'data scarce' areas (Currie and Musango, 2016). Therefore, in cities where informal settlements represent the largest population, the urban metabolism results may not be a complete representation of metabolic flows.

In this regard, using a bottom-up approach to urban metabolism that accounts for human activity measured in time and which is derived from the broader field of societal metabolism, can be useful. Societal metabolism measures the metabolism of human society through characterization of the processes that a society employs to transform energy and materials to ensure its continued existence (Giampietro et al. 2009; Fischer-Kowalski 1998; Fischer-Kowalski and Hüttler 1999; Kovacic and Giampietro 2016). Societal metabolism was first introduced by Marx’s Capital (Foster 1999; Martinez-Alier 2009; Castán Broto et al. 2012) and later taken up by ecological economists (most notably Martinez Alier 
2009) and combined with political ecology (Martinez-Alier et al. 2010). Main attempts to quantify and operationalise societal metabolism relate to the work of Fischer-Kowalski (Fischer-Kowalski 1998; Fischer-Kowalski and Hüttler 1999) and that of Giampietro (Giampietro et al. 2009; Giampietro and Mayumi 2000a; 2000b). The potential here is to utilise the societal metabolism approach to identify both the formal and informal processes that drive urban metabolism.

While the societal metabolism approach has been applied to urban metabolism studies (see for example Ramos-Martín et al. 2009), its application to urban informal settlements is limited (see Royden-Turner 2012; Attia and Khalil, 2015). Existing studies that have applied societal metabolism to informal settlements or slums have utilised a multi-scale integrated analysis of the societal and ecosystem metabolism (MuSIASEM) approach (see for example Miranda et al. 2015; Kovacic and Giampietro 2016; Kovacic et al. 2016; and Smit et al. 2017). The MuSIASEM approach was developed by Giampietro, Mayumi, and Sorman (2012, 2013), and is based on Georgescu-Roegen's flow-fund model (Giampietro and Mayumi 2000a; 2000b).

To our knowledge, theoretical and empirical studies on the metabolism of the informal city ${ }^{2}$ are limited, although a small body of work in this field is emerging. For example, Guibrunet et al. (2016) analyse system boundaries and waste flows as a means to politicize urban metabolism research; Demaria and Schindler (2016) concentrate on waste-to-energy as a means of highlighting contestations over the (re)configuration of urban metabolisms; Attia and Khalil (2015) analyse water flows and quality of life to understand the role of informal areas in achieving sustainable cities; and Kovacic et al. (2016) investigate energy flows and energy policies to address misconceptions of slum communities, and to illuminate inequality and marginalisation. In terms of philosophical underpinnings, 
Guibrunet et al. (2016) confront ontological assumptions about the concept of 'city', whereas Kovacic et al. (2016) deal with the methodological, technical and epistemological uncertainties that characterize energy interventions in urban informal settlements.

This article therefore provides a methodological and empirical contribution on the societal metabolism assessment of the informal city, based on the following two key questions: (i) How can the informal city be measured in terms of metabolic funds and flows? (ii) What are the policy implications of adopting a societal metabolism approach applied to urban informal settlement? The article is organised in the following sections: firstly, the methods utilized and the case study are discussed; secondly, the case study findings regarding the societal metabolism of an urban informal settlement are discussed; and finally, the theoretical, methodological, societal and policy implications of applying the societal metabolism approach to an informal settlement are highlighted.

\section{<heading level $1>$ Methods to quantify informal city societal metabolism}

The MUSIASEM approach consists of five steps, described in Miranda et al. (2015). However, this study was limited to the first two steps, which entails defining the system, in this case an informal settlement, in terms of funds and the system activities in terms of flows. Fund elements in MuSIASEM include: (i) human activity - measured in time; (ii) exosomatic devices in the form of technology and infrastructure; and (iii) land use, while flows are represented by the elements metabolized in the system, which include: (i) food; (ii) energy; (iii) water; (iv) waste; and (v) money. MuSIASEM was thus utilized as an exploratory study of Enkanini informal settlement, incorporating mixed quantitative and qualitative 
methods, in order to understand the use of Time, Money and Energy within the settlement.

Information regarding population dynamics, the flow of money, and energy consumption, are found elsewhere (see Kovacic et al. 2016; Smit et al. 2017; Kovacic and Giampietro 2016), while the analysis of food and waste flows was beyond the scope of the study. In short, the focus of this article was on the fund elements of Enkanini informal settlement, and thus limited to human activity, exosomatic devices and land use.

\section{<heading level 2>Description of the Enkanini informal}

\section{settlement}

Enkanini, which means to 'take by force', is located about four kilometers (approximately 2.5 miles) from the centre of Stellenbosch, an affluent town with high levels of inequality, in South Africa (Western Cape Government 2015). Enkanini informal settlement was established around 2006 through the illegal occupation of municipal land (zoned as agricultural, non-residential land). Attempts at eviction failed due to the fast growth of the settlement and in 2011 , the settlement was enumerated, and a limited number of toilets and taps were provided. Stellenbosch municipality is currently in the process of rezoning the land for residential use (Zibagwe 2016), but it could take a further eight years before the community is connected to the water and electricity grids (Swilling 2014), despite bordering a formalized township with direct electricity access to the north and an industrial area with factories to the south. This suggests that the legality of the informal settlement or residents' rights to tenure is in transition. As per the classification by Smit et al. (2017), Enkanini is transitioning from Category C type: Informal, Illegal, Unplanned, and Illegitimate towards Category D: Informal, Legal, 
Planned, and Legitimate.

Furthermore, the Enkanini informal settlement is fast changing and dynamic; it's population nearly doubling from 4500 (in 2011) to 8000 people (in 2015), whilst the type of households had drastically changed from mostly single adult households (53\% of the population in 2011) to mainly households with 2 or more people (76\% in 2015). Other than the enumeration conducted in 2011, very little is known about the settlement in terms of human activity, land use and infrastructural requirements, thus indicating the need for this type of study to affect planning to meet the service delivery and resource requirements of the settlement.

\section{$<$ heading level 2>Data collection process and tools}

To collect the required data on human activity, household income and energy consumption ${ }^{3}$, fieldwork was conducted in collaboration with the Enkanini Research Centre Association, whereby, five experienced communitybased field researchers administered questionnaires to 100 households ${ }^{4}$. Land use and infrastructure data was captured using GIS; whilst interviews with six community-based field researchers informed qualitative observations, thus verifying context and providing validation of the quantitative data collected.

\section{$<$ heading level 3>Human activity measured in time}

The MuSIASEM approach allocates hours of human activity across several different compartments operating at different hierarchical levels. These different compartments express the key functions performed by society in order to operate and reproduce a socio-economic system (Giampietro et al. 2012). Figure 1 represents the sizes of the various compartments in hours allocated per year, where, at the level of the whole (level n), the total available hours for all sampled 
households for one year is calculated by multiplying 8760 hours in a year by the number of individuals in the sampled households. 


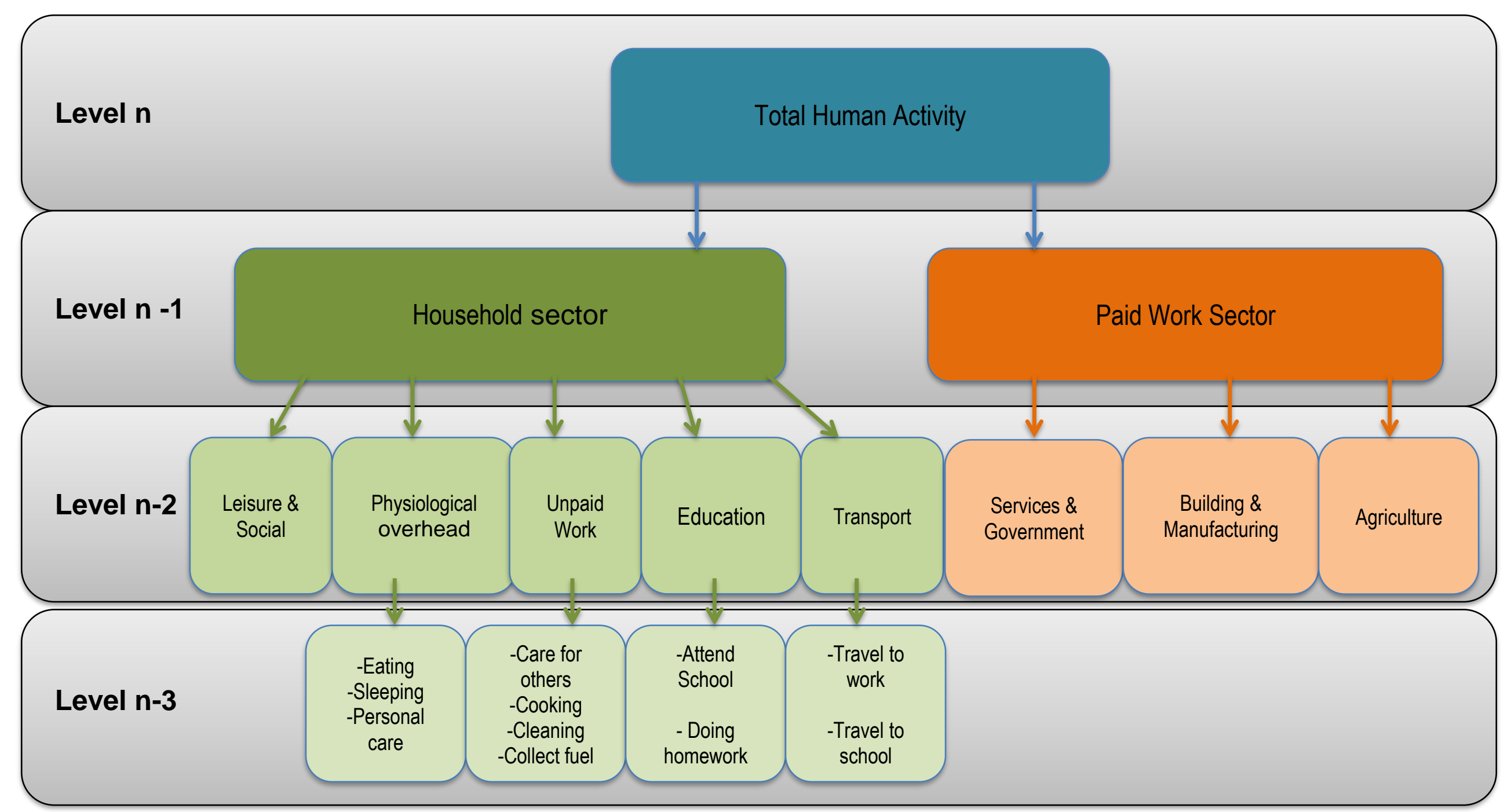

Figure 1: Categories of human activity at different hierarchical levels 
Total Human Activity as indicated in figure 1, can also be calculated as the sum of the total amount of hours spent in the household sector and paid work sector at level $\mathrm{n}-1$. The Household sector includes all the activities carried out outside the Paid Work sector. The pattern of activities in the Household sector can be categorised further at level n-3. In terms of the Paid Work sector, which includes the hours of human activity invested as formal or informal paid work in the economic process, may be assigned to different economic sectors.

\section{<heading level 3>Participatory mapping and livelihood}

\section{mapping using GIS}

Participatory mapping was undertaken in collaboration with five community-based researchers that live in the settlement, using colored markers to identify major roads, infrastructure, social organisations and leisure areas, informal businesses and sectional divisions on an enlarged 2015 Google earth map of the settlement. This was followed with mapping using a GPS device to capture the geographic data pertaining to land use and infrastructure. The process of mapping involved recording the GPS position of each structure, or shack (informally built structures using mainly corrugated iron), within the informal settlement, which was then classified as belonging to energy access, land use or water, waste and sanitation infrastructure categories.

A total of 5866 data points were captured, of which 2786 relate to Energy access, 2859 to Land use, and 221 to Water, waste and sanitation infrastructure. Firstly, Energy access classifications were employed to demonstrate the range of energy carriers used and point to developmental aspects for policy and planning purposes, such as improving overall access to modern and safe energy. Secondly, Land use classifications provided the range of informal 
economy activities, number of social organisations and service providers and also point to livelihood strategies, through a dual-purpose application of residential and business activities within a structure. Whereas Water, waste and sanitation infrastructure classifications were utilised to inform what is needed in terms of formal service delivery.

$<$ heading level $1>$ Societal metabolism of the Enkanini informal settlement

The societal metabolism of Enkanini informal settlement in terms of human activity, land use, and infrastructure and service provision are first presented. This addresses the first question of this article on how the informal city could be measured from a societal metabolism perspective.

\section{$<$ heading level 2>Human activity based on time use in Enkanini informal settlement}

The total available hours for all sampled households in Enkanini for one year was 2137440 hours. This was calculated by multiplying 8760 hours in a year by 244 , the number of individuals in the sampled 100 households. Of the 244 participants in the sample, $48 \%$ were male and $52 \%$ were female. Figure 2 shows that the majority of Total Human Activity for the sampled households is spent in the Household sector (88.3\%), while $11.7 \%$ of time is spent in the Paid work sector. The time use for each of these sectors is elaborated below. 


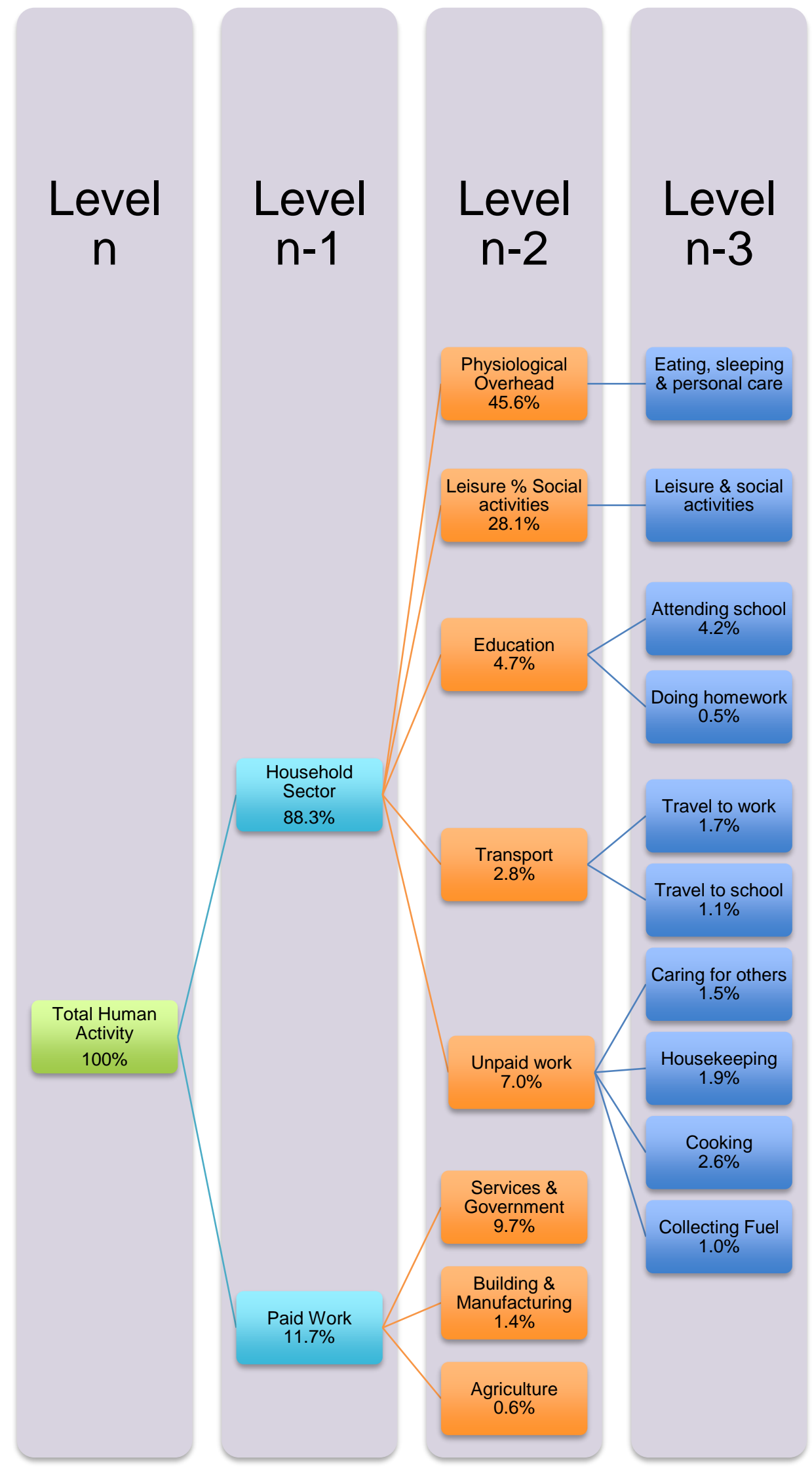

Figure 2: Breakdown of human activities as percentage of Total Human Activity 


\section{<heading level 3>Household sector activities in the Enkanini informal settlement}

Time spent in the Household sector consists of all the hours spent by all persons of working age and non-working age outside of work, including children and unemployed adults. The majority of time spent in the Household sector for the sampled households, relates to $45.6 \%$ in Physiological overhead, which include eating, sleeping and personal care, and $28.1 \%$ in Leisure and social activities. Men and women of all ages spend a median of 3 hours per day on Leisure and social activities, 11 hours per day for eating, sleeping and personal care, and 2 hours per day doing unpaid work. Unpaid work constitutes $7 \%$ of total human activity and includes activities such as cooking, housekeeping, collecting fuel, and caring for others. This proportion is relatively high, considering the Paid Work sector constitutes $11.7 \%$ whilst at national level; Paid Work is estimated to be $6.45 \%$ of total human activity 5 .

Generally, men and women spend the same amount of time cooking and collecting fuel, whilst females spend twice as much time on housekeeping than men in the sample. In terms of participation rates, figure 3 indicates that female participation far outweighs male participation for Unpaid work activities related to caring for others (86\%), housekeeping $(72 \%)$, and cooking $(70 \%)$, whereas the activity collecting fuel is more balanced between male and female participation ( $45 \%$ and $55 \%$ respectively). Therefore, despite the amount of time spent per gender on each Unpaid work activity, overall female participation in these activities is far greater than male participation. 


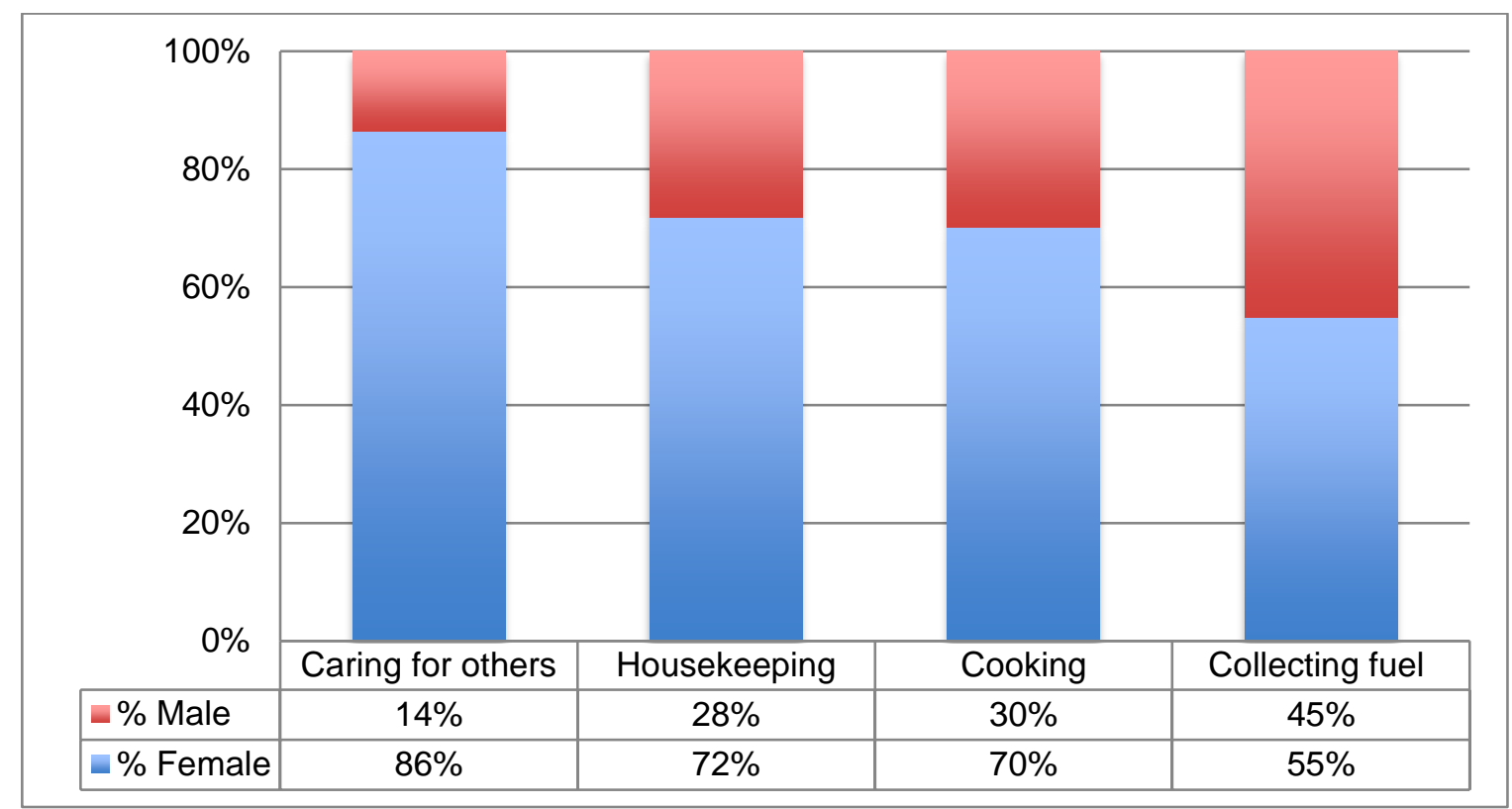

Figure 3: Division of Unpaid Work activities by gender

Although the time spent travelling to and from work contributes to the economic activity, long waiting times and irregular services impact workers available time and could be used more productively. Transport constitutes $2.8 \%$ of Total Human Activity, while travelling to work constitutes $1.7 \%$ and travelling to school constitutes $1.1 \%$ (refer to figure 2). The median time spent on travelling to work on a daily basis is approximately 45 minutes per person, with little difference between men and women ( 43 and 40 minutes respectively). This compares well to the national average of 87 minutes per person per day (StatsSA 2013). There are an equal number of male and female workers (63 per gender) and the preferred mode of transport for both genders is walking (61\%), followed by taking an informally operated mini-bus taxi (17\%) or train (13\%).

The high level of walkers (61\%) combined with cyclists (4\%), indicate that the majority of workers live close to their places of work. The median walking time is approximately 21 minutes per single journey, suggesting that the jobs are 
mostly local to Stellenbosch, thereby indicating that Enkanini residents are economically connected to the wider town. Some individuals in the sampled households indicated frustration with informally operated mini-bus taxi services as being both costly and unreliable, hence the reason for walking to work. On the other hand, those that rely on mini-bus taxis do so due to longer travelling distances (too far to walk), and lack of public transport that connects different work centres. In terms of travel to school, the national average stands at 58 minutes per day (StatsSA 2013), whereas the children of Enkanini spend on average 106 minutes (1hr 45 minutes) travelling to school, whilst half the children travel more than two hours per day. These long travel times may point to a lack of affordable or no-fee schools in the area and/or lack of school buses, thus leaving children to either walk very long distances or having to travel to surrounding towns to gain access to education. Overall, the travel times may indicate the need for affordable, reliable public transport, which is well connected between Stellenbosch and neighbouring towns as well as the need for more no-fee schools in the area.

\section{$<$ heading level 3>Paid work sector in the Enkanini informal}

\section{settlement}

The Paid Work sector constitutes $11.7 \%$ of Total Human Activity for the Enkanini sample, and includes the hours of all individuals who are working either part time or full time. Of the 244 individuals sampled, $64 \%$ are of working age (aged 15 to 64 , but not going to school); $11 \%$ are unemployed, and $2 \%$ are studying, bringing the total number of employed persons to $52 \%$ of the sample population. In comparison, the Paid Work sector for South Africa in 2015 is estimated at $6.45 \%$ of total time available to society, the working age population is similarly around $66 \%$, whilst unemployment is notably higher, averaging at $25 \%$ 
(compared to $11 \%$ in Enkanini) (StatsSA 2015). Futhermore, $80 \%$ of the working age population are in employment, whereas at national level, the labor absorption rate is only $43 \%$ (StatsSA 2015). This signifies that Enkanini is a net provider of labour to the wider community, indicating that it provides more hours of paid work than it requires in terms of schooling, health care, and public services in general.

However, taking a closer look into the working conditions for the Enkanini sample by gender and type of work, that is full time (considered long term, regular work, more than four days a week), and part time (considered as temporary, irregular, seasonal work, or less than three days a week), a different picture in terms of job security and gender emerges (see figure 4).

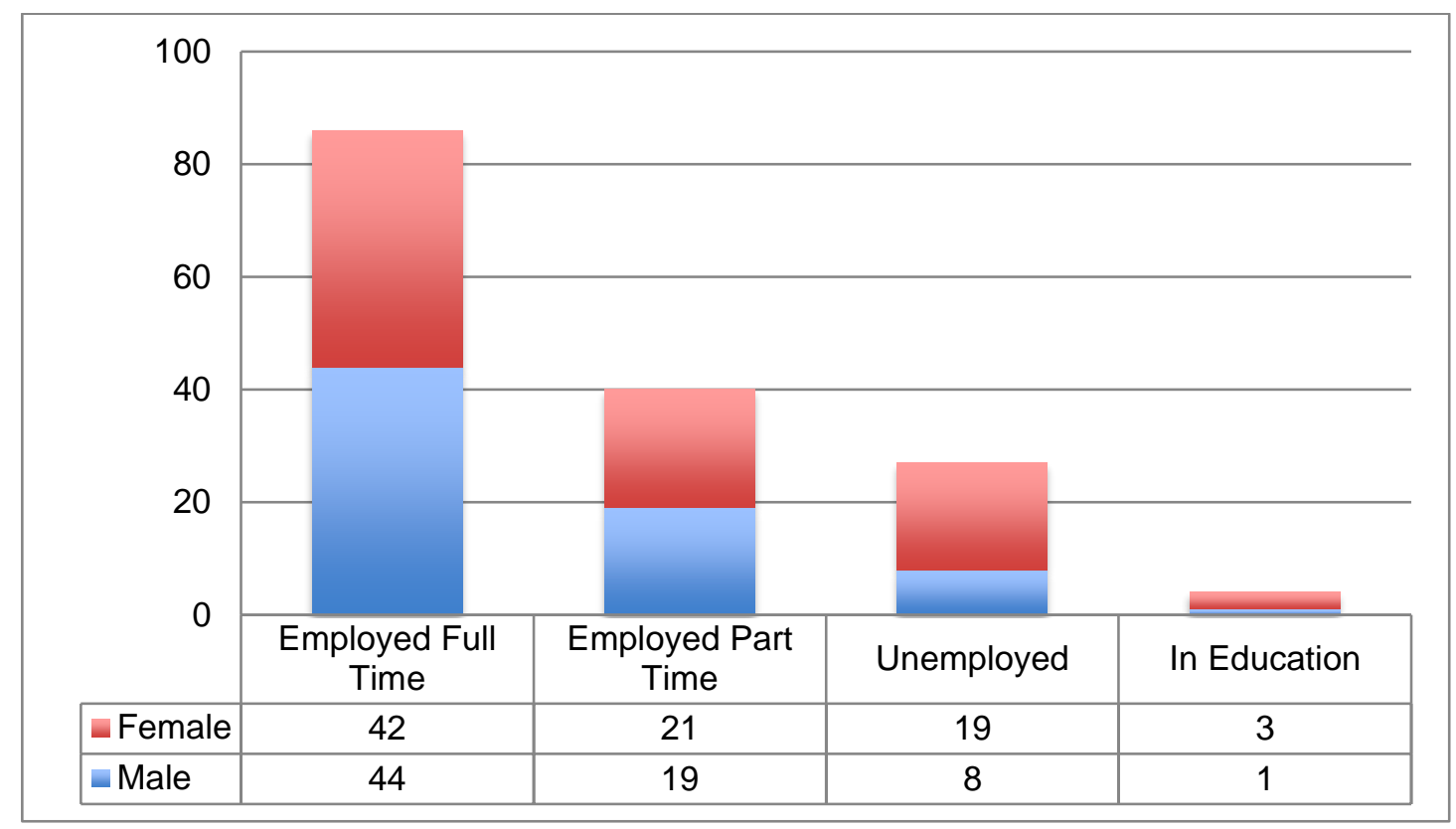

Figure 4: Working age population status by gender

Figure 4 indicates that $32 \%$ of working individuals sampled are in temporary or part time jobs, thus impacting job security and the ability to generate income. A further noticeable trend relates to the gender disparity in unemployed persons, where females constitute $70 \%$, and males $30 \%$ of unemployed persons 
of the sampled individuals. The term unemployed here refers to a person of working age (15 to 64 years) that is not in an education programme and not in any form of employment.

\section{<heading level 3>Employment by sector in the Enkanini informal settlement}

The majority of paid work occurs in the Services and Government sector (83\%), followed by the Building and Manufacturing sector (11\%), and the Agriculture sector (6\%). The Services and Government sector provides the most full time work opportunities overall (63\%), thus offering the most job security and income generating opportunity. In terms of the gender breakdown per sector, figure 5 indicates that whilst Agriculture sector and Services and government sector jobs are equally distributed between men and women, the Energy, building and manufacturing sector jobs are mainly retained by men. Although a wide range of jobs fall within the Services and Government sector, the majority of service work relates to domestic work (24\%) and security work (25\%) with $92 \%$ of domestic work done by women and $92 \%$ of security work done by men. These type of jobs are also indicative of the reliance of higher income groups in the formal parts of the city on the cheap labour provided by informal settlement residents. 


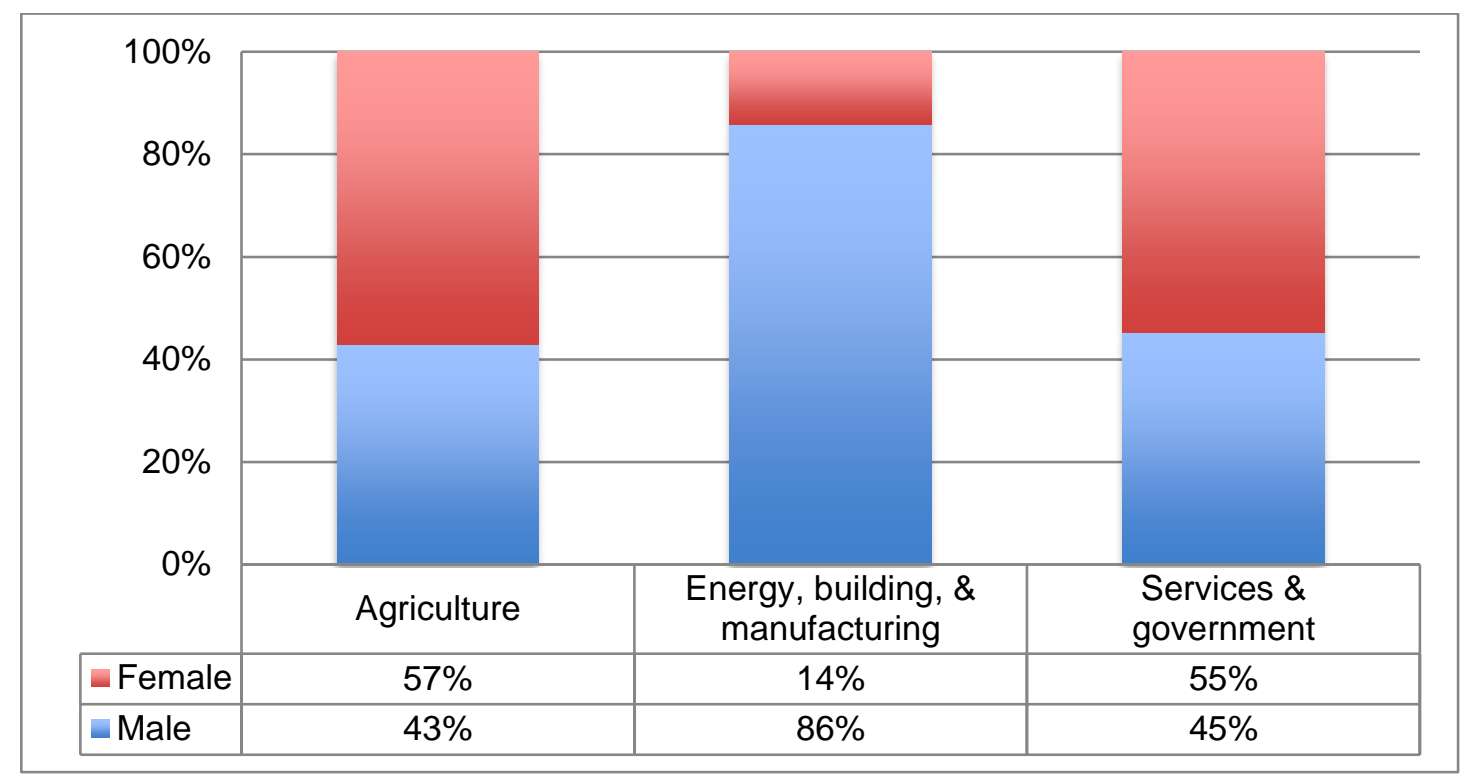

Figure 5: Gender breakdown by sector

$<$ heading level $2>$ Land use and infrastructure mapping results in the Enkanini informal settlement

The results of the GPS mapping are organised per classification category related to: (i) Energy access; (ii) Land use; and (iii) Water, waste and sanitation infrastructure.

\section{<heading level 3>Energy access in Enkanini informal settlement}

Currently, $86 \%$ of South Africans have access to electricity. Whilst South Africa national government aims to achieve universal energy access by 2025, it recognises issues related to electrifying informal settlements (Department of Energy 2017). The Enkanini informal settlement is still classified as an illegal informal settlement, therefore currently no direct grid connected electricity access is available (see figure 6). Consequently, the majority (63\%) of shacks have no access to either solar electricity or indirect grid electricity ${ }^{6}$. These spaces mainly rely on traditional energy carriers, such as paraffin and gas, to supply their energy 
needs. Structures relying mainly on solar electricity, generated through solar photovoltaic (PV) systems ${ }^{7}$, constitute $24 \%$ of the settlement.

Although seemingly a positive development in terms of the adoption of renewable energy, our research indicates that $66 \%$ of solar users do not consider themselves as having access to electricity, whilst the solar PV systems do not fulfill the energy requirements of households, leaving them to supplement with traditional fuels. A similar scenario exists for the $10 \%$ of residents who rely on indirect electricity that also supplement their energy sources, particularly as related to cooking, due to the low capacity of the respective systems. Therefore, any gains made from using modern and safe energy sources such as solar and electricity are lost, as traditional fuels are still the staple whilst indirect electricity connections are prone to causing fires.

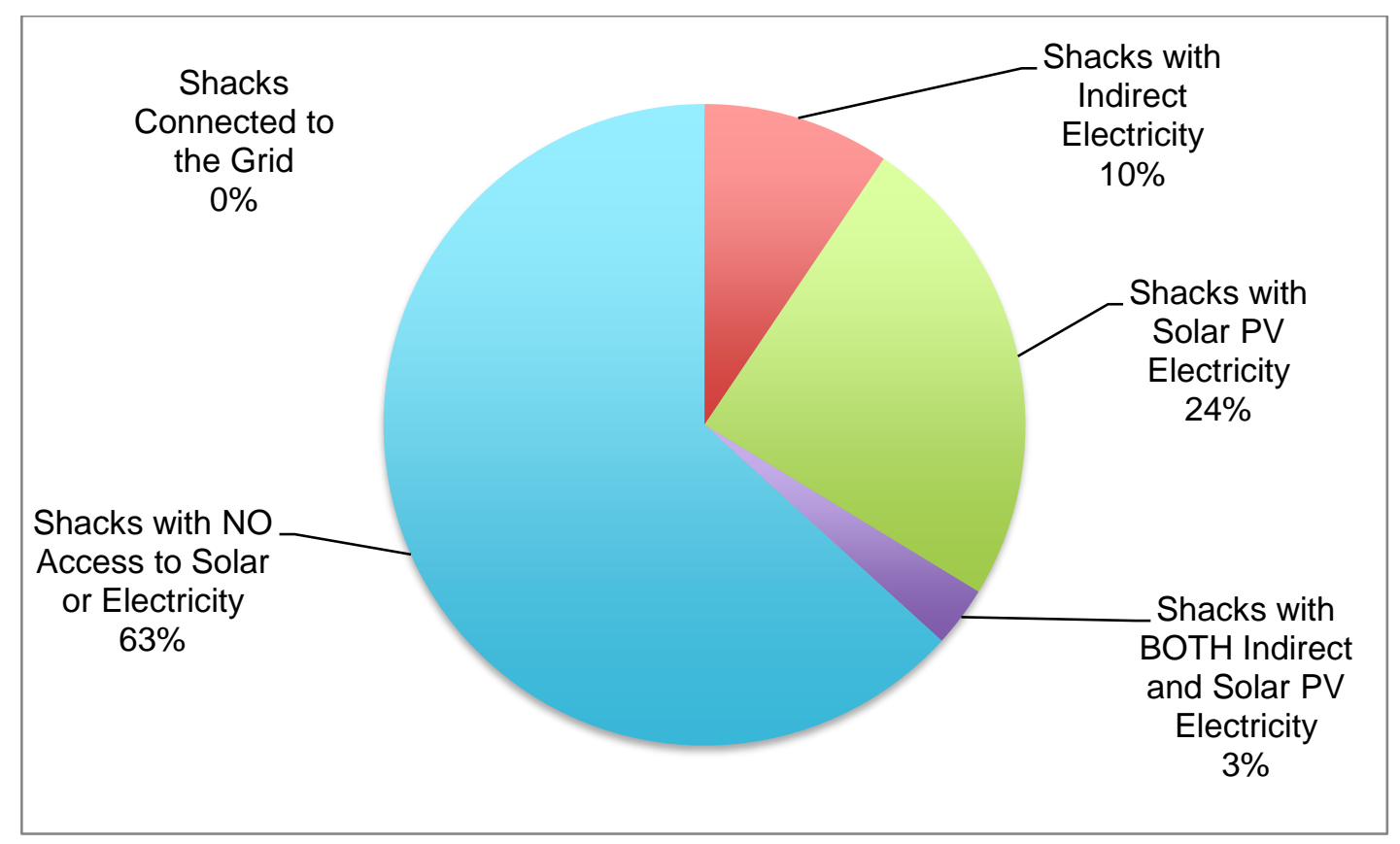




\section{Figure 6: Structures classified by energy access}

\section{<heading level 3>Land use in Enkanini informal settlement}

Although $98 \%$ of the structures in Enkanini are residential only, there is a small but vibrant informal economy offering a range of products and services (see figure 7). Excluding agriculture and forestry, 65\% of economic activities revolve around the sale of food and beverages, followed by service offerings (25\%) including hair and beauty salons, and childcare facilities. Sixty percent of economic activities take place within a residence, whereas activities such as hawking require no structures other than a small table situated at a busy intersection. In terms of agriculture, $2.5 \%$ of residents grow their own food, selling and/or giving the remainder to other households, whereas the commercial animal farms (two relatively large spaces designated for pig and chicken farming) sell directly to residents and local businesses.

Further to economic activity, participants in the participatory mapping exercise indicate that the municipality previously attempted to relocate residents living in the flood prone areas (found in the centre of the map where the rivers converge) to higher ground. However, as the settlement grew, these spaces were reoccupied, mainly by single mothers, which indicate that different vulnerable groups within the settlement live in more precarious areas (Smit 2015). Considering the social dynamics of the settlements, this suggests that a permanent solution be sought in consultation with the residents of the informal settlement. 


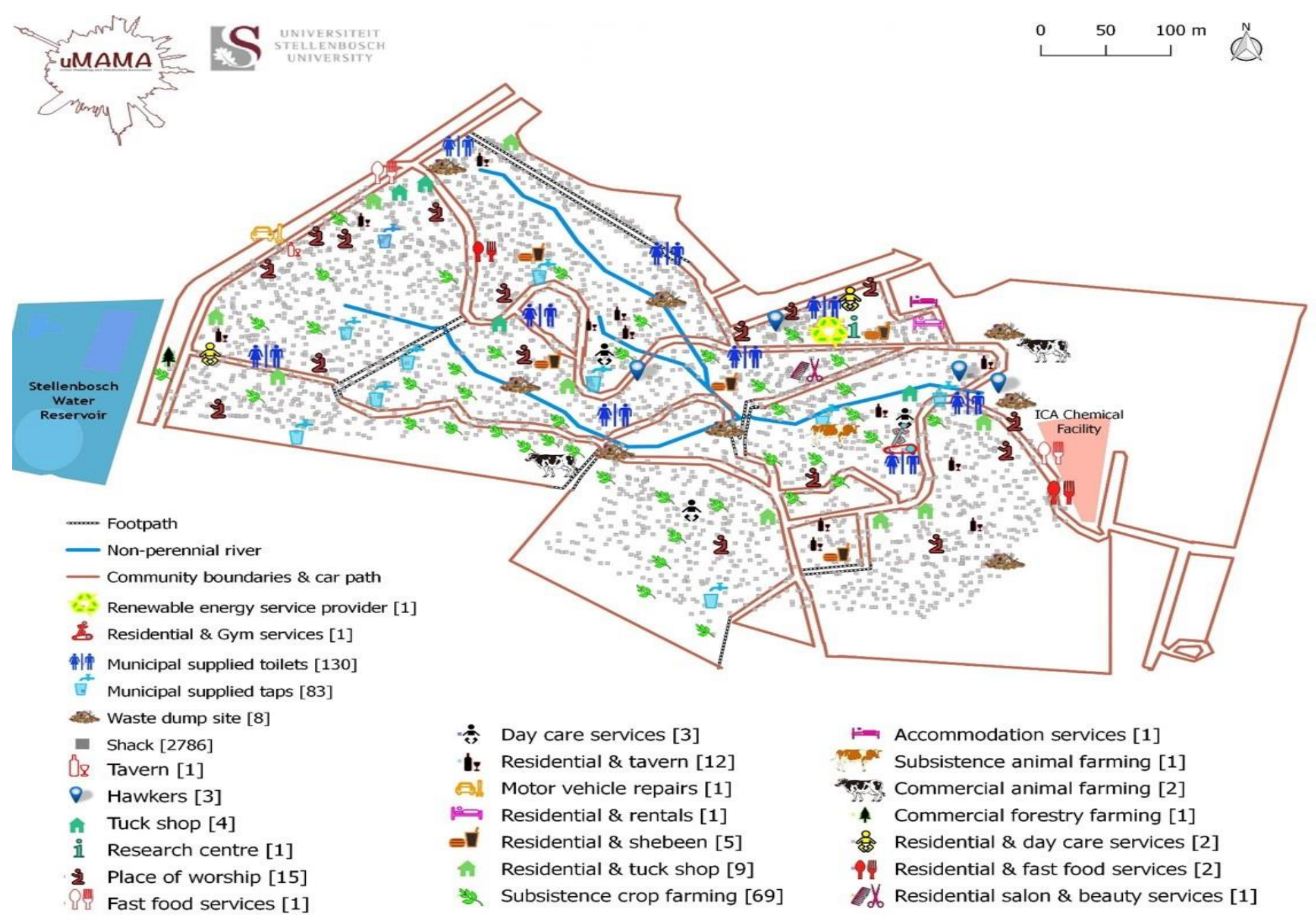


Figure 7: Land use map of Enkanini settlement 
The Enkanini settlement's transport infrastructure is also highly problematic as roads, carved out of the clay soil, are narrow, steep, uneven and slippery, with barely enough space for one car to maneuver. The poor road network has also exacerbated the waste and sanitation problems in the settlement, as waste collection by municipal truck is not possible. Similarly, the footpaths within the settlement require attention as these are frequently lined with sewerage offflow. Whilst creating new road networks and footpaths would improve the health and safety of the daily commute, it would require much consultation with residents, as some dwellings would have to be demolished to make room for new serviceable roads.

$<$ heading level $3>$ Water, waste and sanitation infrastructure in

\section{Enkanini informal settlement}

The water and sanitation infrastructure provided by the municipality illustrated in figure 8 , have become vastly inadequate with the growth of the settlement. This prompted some residents to devise their own solutions in the form of informal connections, including piped tap extensions and toilet facilities within residences ${ }^{8}$. The ratio of households, taken as the number of residential only and dual purpose shacks, to municipal supplied toilets currently stands at 21.2 households per toilet, or 2753 shacks to 130 toilets, whilst the number of households to municipal supplied taps stands at 33.2 households per tap. This means that there are approximately 61.5 people per toilet, which is above the national target of 50 users per communal toilet seat (Department of Water and Sanitation 2017). A further worrying trend is the lack of functional municipalsupplied and serviced refuse removal, leading to the emergence of 8 dumping sites within the settlement. The lack of refuse removal has visibly contributed to the 
deterioration of the overall environment and led to an increase in unsafe and unhealthy conditions. 


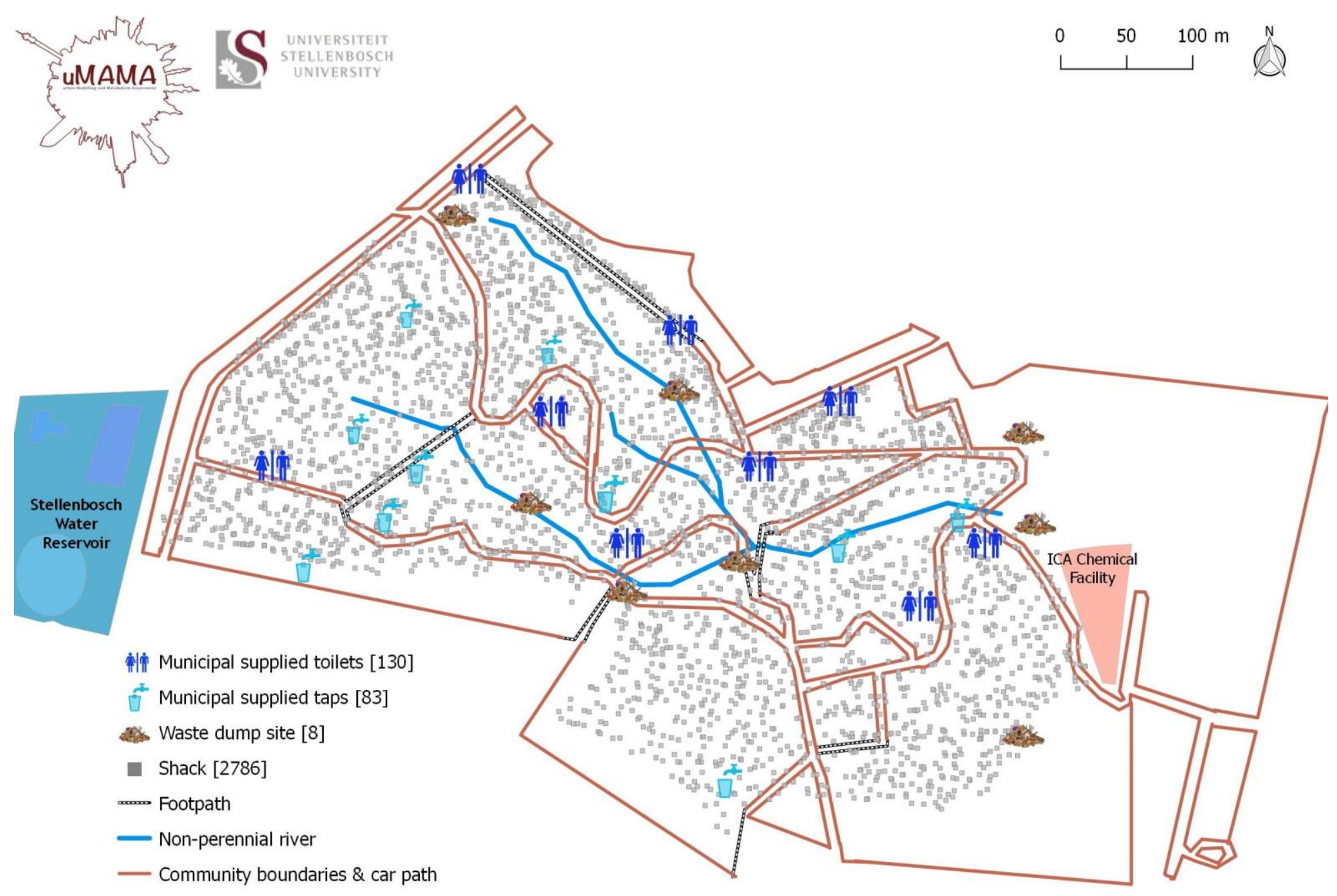

Figure 8: Water, waste, and sanitation infrastructure in Enkanini settlement 


\section{<heading level $1>$ Implications of adopting societal}

\section{metabolism approach applied to urban informal settlement}

This section addresses the second question posed in the article and therefore considers the implications for theory, methodology, society and policy.

\section{$<$ heading level 2>Theoretical implications}

This study has argued that urban informal settlements should be included in urban metabolism analysis, particularly in the developing world where large portions of the urban population live and work in slums. This inclusion would contribute to the realisation of urban metabolism that takes a holistic perspective and seeks to recognise and address resource inequality; whilst providing a more robust analysis of cities based on differentiated urban metabolism.

\section{$<$ heading level 2>Methodological implications}

The MuSIASEM approach was applied in part, as an exploratory study to uncover the societal metabolism of a particular urban informal settlement type. This approach was taken as we recognise that there are different settlement types, which may display different metabolic rates due to their available infrastructure, building types, level of legality or legitimacy, and socio-economic circumstances. The Enkanini case is therefore the first step in analysing these different types of settlements in terms of their societal metabolism. Although the full results of the Enkanini case are not published here, the combination of MUSIASEM with mixed methods, enabled verification and validation of the data produced for analysing human activity, monetary flows, land use and infrastructure. 
Further, the MuSIASEM questionnaire has been replicated in Kayamandi a hybrid, multi-structured settlement type, in Stellenbosch, South Africa. This formed the basis for customizing the MuSIASEM questionnaire for a cross-country comparative analysis currently underway with Mathare in Nairobi, Kenya and Kasubi Kawala in Kampala, Uganda (project LIRA2030-GR09/179 results are forthcoming elsewhere).

In all the cases a sample size was standardized and limited to 100 households. Although the sample size might seem small for larger informal settlements, great care was taken to ensure that the sample is representative of household types, building types, and geographical sections. Furthermore, the objective of the study was to identify patterns or trends in consumption amongst different household types. Once these patterns are identified, energy consumption for the community could be extrapolated by multiplying the median energy usage for each household type with the number of instances of the different household types. This data would be available from national census data, however as demonstrated in the Enkanini case, these spaces are fast changing and require enumeration more frequently than the 10-yearly censuses. In this regard, establishing city observatories that conduct data surveys on a regular basis and

which allow for regular analysis of informal settlements may be useful. The Gauteng City Observatory in South Africa for example conducts surveys every three years to stay abreast of the changes in the Gauteng area.

\section{$<$ heading level 2>Societal implications}

The societal impact of this type of work lies in its ability to give visibility, voice and validity to marginalised communities whilst providing policy makers and local authorities with the tools for dealing with the complexity and 
uncertainty that define urban informal settlements and slums. Whilst the results presented here may not be comprehensive, it is arguably a positive step towards urban and developmental planning that is integrated and inclusive.

\section{<heading level 2>Policy implications: contributions to Urban Agenda Policies}

This study contributes to the international urban policy agenda in several ways. Firstly, by providing societal metabolism data for informal settlements described as data scarce areas; thus contributing to the development of standardized metrics such as ISO 37120 as promoted by the World Council for City Data (WCCD, 2017). Secondly, by enhancing the relevance of the concept of urban metabolism and its application to the developing world context through an exploratory study that initiated cross-country comparative studies in Africa. Thirdly, by providing empirical evidence, utilizing mixed and unconventional approaches to urban metabolism assessments; thus contributing to the need, recently highlighted in the Sustainable Development Goals report (UN 2017a), for disaggregated data and new methodologies that ensure quality and reliability of data. Finally, as informing standards and principles for planning sustainable and equitable urban areas promoted through the five pillars of the New Urban Agenda (UN 2017b).

\section{$<$ heading level $1>$ Conclusion}

This article considers how the informal city may be quantified in terms of societal metabolism and what the implications of such an application is to theory, methodology, society, and policy. A multi-scale integrated assessment of the societal and ecosystem metabolism (MuSIASEM) approach, in combination with mixed quantitative and qualitative methods, is promoted as an appropriate 
methodology for quantifying the informal city in terms of funds and flows; although only fund data is presented here. The MuSIASEM approach enables the analysis of informal economic activities through time use surveys, whilst capturing developmental and infrastructural requirements through participatory and GIS mapping. The data scarcity in informal settlements necessitates that human activity, measured in time, is captured at the household and individual levels to represent the societal metabolism of the settlement. In this regard, MuSIASEM provides disaggregated data on the societal metabolism which can be used to compare different households, social groups, neighborhoods et cetera; making it possible to interface the results of MuSIASEM with the analysis of political aspects related to age, gender, and socio-economic profile.

The analysis of human activity suggests that Enkanini residents are a net provider of labor to wealthier parts of Stellenbosch. Furthermore, Enkanini residents are far more economically active than the national average. Land use results point to a number of informal economy and livelihood activities, in the form of dual-purpose structures for residential and business activities; whilst water, waste and sanitation infrastructure is found to be grossly inadequate. Furthermore, energy access remains constrained due to the lack of direct electricity connections and/or alternatives that fulfill the energy requirements of residents.

Furthermore, the implications of applying societal metabolism to an urban informal settlement relate to theoretical contributions to the field of urban metabolism; methodological contributions through the replication of the study in other African cities; societal impact of representing marginalised communities, previously neglected in urban metabolism; and as informing international urban policy, standards and metrics. 
The Enkanini case does not deliver a comprehensive set of metabolism results, however as an exploratory study into the societal metabolism of slums it has led to and informed several subsequent studies. Additionally, the lessons learnt from the application of MuSIASEM to a particular informal settlement type, contributes to the development and improvement of the method for future cases. Data collection from a bottom-up perspective may be time consuming and costly, however the data scarcity and persistence of these spaces warrant in-depth analysis for sustainable, and equitable urban planning. Going forward, the authors intend to continue with the expanded rollout and improvement of MuSIASEM for analysing different slums types in the urban African context. 


\section{<heading level 1>Acknowledgements}

This study is based on Suzanne Smit's Ph.D. in which the Enkanini case study was carried out as part of the Participatory Integrated Assessment of Energy Systems to Promote Energy Access and Efficiency (PARTICIPIA) project. This work was funded under the ACP-EU Cooperation Programme in Higher Education (EDULINK); a programme of the ACP Group of States, with the financial assistance of the European Union (contract DCI-AFS/2013/320-333). However, the contents of this publication are the sole responsibility of the authors and can in no way be taken to reflect the views of the ACP Group of States or the European Union. The PhD study is also being funded through the Southern African Systems Analysis Centre. GIS research assistance provided by Nhlanhla May.

\section{$<$ heading level 1>Notes (Please see end of document, the auto format placed endnotes after the references)}

\section{<heading level 1> About the Authors}

Suzanne Smit is a Ph.D. candidate in Sustainable Development at the School of Public Leadership in Stellenbosch University, South Africa and executive board member of the urban Modelling and Metabolism Assessment (UMAMA) research team.

Josephine Kaviti Musango is an Associate Professor at the School of Public Leadership, and Founder and Executive Director for urban Modelling and Metabolism Assessment (UMAMA) research team within the Centre for Complex Systems in Transition (CST) at Stellenbosch University, South Africa. Her ongoing 
research relates to the application of system dynamics modelling in managing change in resource-management and policy-related challenges, especially in the energy sector, green economy, and African cities resources issues.

Zora Kovacic is a Postdoctoral Fellow with the urban Modelling and Metabolism Assessment (UMAMA) research team, School of Public Leadership, Stellenbosch University, and a Postdoctoral Researcher at the Institut de Ciencia i Tecnologia Ambientals (ICTA), Universitat Autonoma de Barcelona.

Alan Brent is a Professor and the inaugural holder of the Chair in Sustainable Energy Systems at Victoria University of Wellington, New Zealand. He is an Extraordinary Professor of Engineering Management and Sustainable Systems in the Department of Industrial Engineering at Stellenbosch University, South Africa.

\section{$<$ heading level $1>$ References}

Attia, S. \& H.A.E. Khalil. 2015. Urban metabolism and quality of life in informal areas. Proceedings of the 20th International Conference on Urban Planning, Regional Development and Information Society. (REAL CORP) 2015 Tagungsband, 5-7 May 2015, Ghent, Belgium.

Beloin-Saint-Pierre, D., B. Rugani, S. Lasvaux, A. Mailhac, E. Popovici, G. Sibiude, E. Benetto, and N. Schiopu. 2016. A review of urban metabolism studies to identify key methodological choices for future harmonization and implementation. Journal of Cleaner Production, 163(1): 223-240.

Castán Broto, V., A. Allen, and E. Rapoport. 2012. Interdisciplinary perspectives on urban metabolism. Journal of Industrial Ecology, 16(6):851-861. 
Currie, P.K., and J.K. Musango. 2016. African Urbanization: Assimilating urban metabolism into sustainability discourse and practice. Journal of Industrial Ecology, 21(5):1262-1276.

Demaria, F. and S. Schindler. 2016. Contesting urban metabolism: Struggles over waste-to-energy in Delhi, India. Antipode, 48: 293-313.

Department of Energy (South Africa). 2017. Integrated national electrification programme. Access 20 March 2018 from: www.energy.gov.za/files/INEP/inep_overview.html

Department of Water and Sanitation (South Africa) 2017. National norms and standards for domestic water and sanitation services: Version 3-Final. Accessed 22 March 2018 from: https://cer.org.za/wpcontent/uploads/2017/09/National-norms-and-standards-for-domensticwater-and-sanitation-services.pdf

Fischer-Kowalski, M. 1998. Metabolism: The intellectual history of material flow analysis Part I, 1860 - 1970. Journal of Industrial Ecology, 2(1):61-78.

Fischer-Kowalski, M. and W. Hüttler. 1999. Society's metabolism: The intellectual history of materials flow analysis, Part II, 1970 - 1998. Journal of Industrial Ecology, 2(4): 107-136.

Foster, J.B. 1999. Marx's theory of metabolic rift: Classical foundations for environmental sociology. American Journal of Sociology, 105(2): 366-405.

Giampietro, M. and K. Mayumi. 2000a. Multiple-scale integrated assessment of societal metabolism: Introducing the approach. Population and Environment, 22: 109-153.

Giampietro, M. and K. Mayumi. 2000b. Multiple-scale integrated assessment of societal metabolism: Integrating biophysical and economic representations across scales. Population and Environment, 22: 155-210. 
Giampietro, M., K. Mayumi, and R. Ramos-Martin. 2009. Multi-scale integrated analysis of societal and ecosystem metabolism (MuSIASEM): Theoretical concepts and basic rationale. Energy, 34: 313-322.

Giampietro, M., K. Mayumi, and A.H. Sorman. 2012. The metabolic pattern of societies-Where economists fall short. Abingdon: Routledge.

Giampietro, M., R.J. Aspinall, S.G.F. Bukkens, J.C. Benalcazar, F. Diaz-Maurin, A. Flammini, T. Gomiero, Z. Kovacic, C. Madrid, J. Ramos-Martin, and T. Serrano-Tovar. 2013. An innovative accounting framework for the FoodEnergy-Water Nexus: Application of the MuSIASEM approach to three case studies. Environment and Natural Resources Working Paper No.56 - Food and Agriculture Organization of the United Nations (FAO), Rome, 2013.

Guibrunet, L. and V. Castán Broto. 2015. The sustainability of the informal city: An urban metabolism approach. Paper presented at the 11th International Conference of the European Society for Ecological Economics (ESEE), Leeds, UK on 30 June - 3 July 2015.

Guibrunet, L., M. Sanzana Calvet, and V. Castán Broto. 2016. Flows, system boundaries and the politics of urban metabolism: Waste management in Mexico City and Santiago de Chile. Geoforum, 85:353-367..

Horta, M. and J. Keirstead. 2016. Downscaling aggregate urban metabolism accounts to local districts. Journal of Industrial Ecology, 12(2): 294-306.

Jalas, M. 2002. A time use perspective on the materials intensity of consumption. Ecological Economics, 41: 109-123.

Kennedy, C., J. Cuddihy, and J. Enegel-yan. 2007. The changing metabolism of cities. Journal of Industrial Ecology, 11:43-59.

Kennedy, C. and D. Hoornweg. 2012. Mainstreaming urban metabolism. Journal of Industrial Ecology, 16(6): 780-782. 
Kennedy, C., S. Pincetl, and P. Bunje. 2011. The study of urban metabolism and its applications to urban planning and design. Environmental Pollution, 159 (8-9): 1965-1973.

Kovacic, Z. and M. Giampietro. 2016. Between theory and quantification: An integrated analysis of metabolic patterns of informal urban settlements. Energy Policy, 100: 377-386.

Kovacic, Z., S. Smit, J.K. Musango, A.C. Brent, and M. Giampietro. 2016. Probing uncertainty levels of electrification in informal urban settlements: A case from South Africa. Habitat International, 56: 212-221.

Martinez-Alier, J. 2009. Social metabolism, ecological distribution conflicts and valuation languages. Capitalism Nature Socialism, 20(1):58-87.

Martinez-Alier, J., G. Kallis, S. Veythey, M. Walter, and L. Temper,. 2010. Social metabolism, ecological distribution conflicts and valuation languages. Ecological Economics, 70: 153-158.

Miranda, M., V. Santos, and M. Giampietro, M. 2015. Informal settlements as Socio-Ecological Systems: The metabolic pattern of the Vidigal slum in Rio de Janeiro, Brazil. 2nd International Conference on Energy \& Environment (ICEE), 18-19 June 2015, Guimarães, Portugal

Musango, J.K., P. Currie, and B. Robinson. 2017. Urban metabolism for resource efficient cities: from theory to implementation. Paris: UN Environment.

Newell, J.P. and J.J. Cousins. 2015. The boundaries of urban metabolism: Towards a political-industrial ecology. Progress in Human Geography. 39: $702-728$

Pincetl, S., P. Bunje, and T. Holmes. 2012. An expanded urban metabolism method: Toward a systems approach for assessing urban energy processes and causes. Landscape and Urban Planning, 107:193-202. 
Ramos-Martín, J., S. Cañellas-Boltà, M. Giampietro, and G. Gamboa. 2009. Catalonia's energy metabolism: using the MuSIASEM approach at different scales. Energy Policy, 37:4658-4671.

Royden-Turner, S. 2012. From Eradication To Intervention: Urban Informal Ecosystem. Masters Thesis. University of Cape Town, Cape Town, South Africa.

Smit, S. 2015. Notes from group participatory mapping. Enkanini Research Centre, Stellenbosch, South Africa, November 2016.

Smit, S., J.K. Musango, Z. Kovacic, and A.C. Brent. 2017. Conceptualising slum in an urban African context. Cities, 62: 107 - 109.

StatsSA (Statistics South Africa). 2013. A survey of time use, 2010. Pretoria: Statistics South Africa.

StatsSA (Statistics South Africa). 2015. Quarterly Labour Force Survey: Quarter 4, 2015. Pretoria: Statistics South Africa.

Swilling, M. 2014. Rethinking the science-policy interface in South Africa: Experiments in knowledge co-production. South African Journal of Science, 110(5/6): 78-84.

UN (United Nations). 2017a. The sustainable development goals report 2017. United Nations: New York.

UN (United Nations). 2017b. New Urban Agenda. www.habitat3.org. Accessed 26 March 2018.

UN-Habitat (United Nations - Human Settlements Programme). 2010. The challenge of slums. Global report on Human settlements: revised and updated version (April, 2010). Accessed 8 February 2016, from http://unhabitat.org/wpcontent/uploads/2003/07/GRHS_2003_Chapter_01_Revised_2010.pdf 
Western Cape Government, Provincial Treasury. 2015. Socio-economic profile: Stellenbosch Municipality 2015. Accessed 19 March 2018 from: www.westerncape.gov.za/assets/departments/treasury/Documents/Socioeconomic-profiles/2016/municipality/Cape-WinelandsDistrict/wc024_stellenbosch_2015_sep-Ig_profile.pdf

World Bank. 2016. Overview of South Africa. Accessed 2 February 2017 from: www.worldbank.org/en/country/southafrica/overview\#1

WCCD (World Council on City Data). 2017. www.dataforcities.org. Accessed 26 March 2018.

Zibagwe, S. 2016. Struggle for urban citizenship in South Africa: Agency and politics in the Enkanini upgrading project, Stellenbosch. Ph.D. thesis. Stellenbosch University, Stellenboch, South Africa.

$<$ heading level $1>$ Notes

${ }^{1}$ Conventional urban metabolism methods include economy-wide material flow analyses; ecological footprint analyses; input-output analyses; energy assessments; life cycle assessments; network analyses; and combinations of these methods (Beloin-Saint-Pierre et al. 2016; Musango et al. 2017).

${ }^{2}$ Within this article, the informal city is represented through an urban informal settlement, which encompasses a particular spatial organisation, with its own informal economy, and responses to poor infrastructure and service delivery. We thus recognise informal settlements as having their own patterns of consumption and production, and informal processes.

3 It should be noted that energy consumption data was limited to quantities of traditional fuels, such as paraffin and gas, used per household per month; and changes in energy mix over time (see Kovacic et al. 2016). This is due to the fact that indirect electricity and solar PV electricity use is not metered. The survey originally did not account for this. This limitation prompted a follow-up study, currently underway, which would calculate electric and solar PV energy consumption.

${ }^{4}$ Although the sample size is comparatively small for a population of 2800 households, the objective of the study was to identify patterns or trends in consumption amongst different household types.

${ }^{5}$ Paid Work data estimated by authors based on national labor force survey (StatsSA 2015) 
6 Indirect electricity users obtain electricity through informal connections via a neighbor from the Kayamandi settlement (situated to the north of Enkanini) who are formally and directly connected to the electricity grid. Indirect electricity users purchase prepaid electricity vouchers that are passed on to the owner of the formal connection. As there is no record kept of actual electricity use by the indirect user, this arrangement relies heavily on trust.

7 For more information see http://www.ishackproject.co.za/

8 Due to confidentiality and the sensitive nature of this information, the informal connections that were observed are not indicated on the map for ethical reasons. 9 Project information available at: http://codec.livinglab.co.ke/ 